\title{
Volunteer Scheme for Dysphasia and Allied Problems in Stroke Patients
}

\author{
VALERIE EATON GRIFFITH
}

British Medical fournal, 1975, 3, 633-635

With nearly 100000 heavily handicapped hemiplegics in Great Britain ${ }^{1}$ stroke is a major medical problem. Though most stroke patients benefit from their period of rehabilitation there inevitably comes a time when, with many problems remaining, they are discharged home to their families. The despair felt by the patient and his relatives may be overwhelming, and in most cases little support is available. The problem is particularly acute when speech is affected since there is a national shortagein some areas a total absence-of speech therapists. One source of help which has not been fully explored is the use of volunteer helpers working within a responsible organization and cooperating with doctors, speech therapists, and other professional workers. Such a project has been sponsored by the Chest and Heart Association and financed by the Clarkson Foundation. This report describes the pilot scheme and records some observations made after 16 months' work in two areas, the Chilterns and Oxford city.

\section{General Plan}

The scheme concerned patients with speech and allied disorders and was based on methods used by untrained volunteers working with two dysphasic stroke patients. ${ }^{2}$ Volunteers were recruited to visit each patient regularly and provide weekly "club" meetings with other patients and their relatives.

Supervisors.-The pilot scheme was administered by a single organizer with a supervisor in each area. The supervisor made a preliminary visit to the home of each patient, her attitude being that

Great Missenden, Buckinghamshir

VALERIE EATON GRIFFITH, Originator of Scheme. of a neighbour offering help. She asked the patient and his family what help they needed-for instance, in talking, writing, dealing with numbers, or telling the time-and she built up a picture of the patient's interests, home, and family. From this information, together with any advice from the general practitioner and speech therapist, a programme of work was made up for the volunteers' visits.

Volunteers.-At the time of writing 200 volunteers had been recruited, 190 of whom were women. Most were housewives, and many had been nurses or teachers before marriage; some were still working. Nobody had any training for this work; common sense, the ability to observe, and the desire to help were the only requirements. A team of two to seven volunteers was assigned to each patient. The team was selected from those who lived nearby and, where possible, shared the patient's interests-for instance, a patient and a volunteer who shared a passion for racing worked well together to improve the patient's aptitude with money and numbers. A preliminary meeting of the team and the supervisor was held to discuss the patient's wishes and needs. The need for an informal and neighbourly approach was emphasized, the chief aim being stimulation and the return of hope and confidence.

Home Visits. - Approaches varied, but at the first visit a volunteer broke the ice and learnt about the patient, often by a " 20 questions"type quiz. Suitable games were then introduced based on the programme (see Appendix). Slowly, as the relationship developed and confidence returned, more sophisticated material was introduced and "homework" left to occupy the time between visits. Every three months the team meet the supervisor to discuss progress and plan future work.

Clubs were held in the village hall and handicapped centre and were organized by the supervisor and run with the help of volunteers. Once a week the patients spent two hours at the club. Transport was arranged. The patients' families were made welcome and encouraged to take an interest in the other patients to gain, perhaps, a little objective vision. The club's activities were directed towards general progress but the first essential was that the afternoon should be enjoyed. The many games included general questions round the table with answers spoken, written, mimed, or drawn; bingo with numbers, words, shapes, colours, and symbols; charade miming; giant community crosswords; and darts, skittles, and bar billiards. From time to time the routine of the club was varied by film shows, left-handed cooking demonstrations, and outings. 
Speech Therapists provided generous support and became more involved as time went on; some offered, for instance, to attend the team meetings. Volunteers also knew that they could contact the speech therapists for advice, and in the Chilterns the resident speech therapist took a full part in assessing the patients and held group therapy sessions at the club.

\section{Patients}

Thirty-one patients, 18 men and 13 women, were referred to the scheme by consultants at general or rehabilitation hospitals or by general practitioners (see table). Each doctor was kept informed of the programme for his patient and after about nine months he was asked to assess the patient's progress. When first seen all 31 patients were depressed and either too apathetic or too frustrated and irritable to use fully their remaining faculties. It was common, for example, to find the patient seated in a chair turned to the wall. In many cases the patients' families were overwhelmed by the immensity of the burden. Often friends and neighbours felt embarrassed by the situation and stopped visiting, which only added to the sense of isolation.

Age Groups and Length of Time since Stroke in 31 Patients in Scheme

\begin{tabular}{|c|c|c|c|c|c|c|c|c|c|c|c|c|}
\hline & \multicolumn{5}{|c|}{ Age (Years) } & \multicolumn{7}{|c|}{ Period since Stroke (Years) } \\
\hline & $\leqslant 44$ & $4-54$ & -64 & -74 & $4 \geqslant 75$ & $<1$ & 1 & 2 & 3 & 4 & 7 & 11 \\
\hline No. of patients & 2 & 10 & 8 & 10 & 1 & 18 & 6 & 2 & 2 & 1 & 1 & 1 \\
\hline
\end{tabular}

Physical State.-All 31 patients had hemiplegia involving the dominant side; in all but one this was the right side. On entry to the scheme nine patients were chair bound, eight were walking with considerable support, and eight were walking with a stick. The remaining six were walking unaided.

Speech.-According to the speech therapists' assessments, in 22 patients dysphasia or dyspraxia was moderate to severe and in seven mild. The remaining two patients had severe dysarthria only. Two patients with mild dysphasia had moderately severe dysarthria as well.

\section{Results}

\section{ASSESSMENT OF IMPROVEMENT}

Speech and Understanding.-The assessment of improvement was based on: the opinion of the family doctor; an assessment by the speech therapist in 19 of the 31 patients; and a group assessment by the supervisor and a team of volunteers responsible for the patient. The volunteers took into account the performance of the patient in quiz games, the level and extent of conversation, and family comments. For example, one man who had refused to contact his friends before the start of the scheme began to telephone them to arrange meetings after a few weeks. Every patient was seen and the speech assessed by the general practitioner after about nine months in the scheme. In the doctors' opinion 21 patients had improved, and in 17 of the 19 patients seen by the speech therapist her assessment agreed with that of the doctor. The volunteers agreed with the doctors' assessments in 20 of the 21 patients. Of the 10 patients assessed by the doctors as not having improved seven had severe dysphasia or dyspraxia. Nevertheless, three of these patients had learnt to say "yes" and "no" and a few nouns correctly, which was of inestimable value to both them and their families. All 10 patients had also learnt to communicate better by either miming or drawing.

Reading.- Twenty of the 29 patients in whom reading was affected improved. This assessment was made by the volunteers based on the length and difficulty of material read, progressing from newspaper headlines to paragraphs, pages, and stories. The time taken to read a paragraph was noted and the patient either answered questions or drew pictures about the content.

Writing.-Sixteen of the 29 patients whose writing was affected improved. Progress was assessed by their performance in, for example, copying and writing postcards or letters. Where speech therapists gave an assessment on reading and writing their opinion was taken; this usually agreed with that of the volunteers, but where they differed it is reassuring that the volunteers were usually more strict in their judgement than the professionals.
Memory, Money, Numbers, Shapes, Calendar, Time, and Colours.As there was usually no professional assessment for these, improvement was assessed by the volunteers using the simple objective methods described in the appendix.

Concentration, Alertness, and Observation (see Appendix).-Nearly all the patients when first seen had great difficulty in concentrating and were too withdrawn to observe or comment. Twenty-seven patients improved considerably. Many of these patients were eventually able to play card games such as bridge for long periods.

Use of Hands.-Patients were encouraged to use their hands by means of crafts and puzzles, etc. Out of seven patients whose strokes were relatively recent and whose right hands were not severely affected four improved. Nineteen of the 20 patients who had to learn to use their left hand improved; the remaining patient was already skilful with his left hand. Crafts proved an absorbing and satisfying hobby and speech often became easier while the patients' hands were occupied.

General Confidence.-Each patient's general practitioner was asked if he felt there had been a change in the patient's general confidence and attitude to life and, if so, whether the scheme had contributed to this improvement. In all but one of the patients the doctor reported an improvement to which, in his opinion, the scheme had contributed. The single failure was a man of 76 who was very frail when first seen. Since some of the patients who showed great improvement were in their early 70s age was evidently not the decisive factor; physical strength and fighting spirit were far more important. The patients whose strokes occurred seven and 11 years before entry were also considered by the doctor to have shown some improvement. This suggests that a long period since the stroke does not exclude further progress, given strength and willpower in the patient, but the scheme is not suitable for the very old or frail.

\section{COST OF SCHEME}

This pilot scheme was based on two areas, one urban and one rural, each with a population of about 250000 , corresponding to that usually administered by the district management team. The cost of the scheme at 1973 levels in each area was $£ 1700$ yearly. The supervisors were paid at the half-time rate of a medical social worker with additional expenses which also covered one speech therapist's sessions.

\section{Discussion}

As amateurs we came to appreciate the immense complexity of dysphasia and allied problems after stroke, and we fully acknowledge that when improvement has occurred it must have been due to several factors. Some of the 31 patients were having additional speech therapy for all or part of the time they were in the scheme and some were also attending weekly centres outside the scheme; some families were better at coping with the patient than others; and, most important of all, the fighting spirit and determination of the patients varied greatly. Spontaneous improvement must also be taken into consideration. Nevertheless, at its lowest valuation we feel that the scheme has contributed to the confidence, happiness, and general attitude to life in 30 of the 31 patients, and this has been confirmed by the opinion of the general practitioners. There are several reasons for this.

Firstly, we offered help as neighbours and did not judge or comment on the disability; we accepted it. Secondly, because we did not know the patient before the stroke he felt none of the shame with us which he felt with his family and friends who were so shocked by the change in him; he had no need to try to hide his inadequacies and would therefore make greater efforts to talk with us. (The shame and the attempts to disguise handicaps were at their worst with highly intelligent people who have held responsible jobs.) Thirdly, during their visits the volunteers took time to encourage the patient's independence. They waited while he struggled to find the right word, pick up a pencil, or prepare a precarious cup of coffee. Overprotection by the family from the best motives was almost universal and could destroy whatever desire for independence remained; because they were not related to the patient the volunteers could help restore it. 
Fourthly, we filled the gaps in the weeks between whatever professional help was available. Speech therapy was seldom more than one hour a week, and because of the shortage of speech therapists and the vagaries of transport it was rarely as much. Our visits, and the club, aimed to occupy part of every weekday, and the stimulation of the patient was therefore almost continuous. It became clear that however great the speech disability the resulting depression and apathy were an even greater handicap. Once these were overcome the patient would find a way to communicate. The response to the stimulation of the visits was an increased confidence and alertness which meant, in the words of a senior speech therapist, that "the patients arrive for treatment in a receptive state of mind, cheerful, and eager to work." This enabled the best possible use to be made of the professional help available and also helped to prevent the slipping back into apathy which may happen all too readily between sessions. Finally, the volunteers' regular visits over several months supported the family and helped to dispel the almost superstitious fear of the patient's inability to speak which prevented visits from neighbours and friends.

It cannot be emphasized too emphatically or too often that this volunteer scheme does not claim nor is it an attempt to replace professional speech or occupational therapy or rehabilitation of any kind. The volunteers are not and should not be trained; if they were they would lose their most valuable asset, which is to approach and be welcomed by the patient and the family as a helping neighbour.

I am greatly indebted to the Chest and Heart Association and the Clarkson Foundation. I thank also the consultants, general practitioners, speech therapists, district management team, area health authority, and many others for their support, and above all the supervisors and volunteers. I am glad to acknowledge the help of Mr. W. B. Fletcher, Dr. C. L. Miller, and Dr. T. M. Pollock in the design of the records and the preparation of the report.

\section{Appendix}

\section{WAYS USED TO MEASURE PROGRESS}

Memory.-(a) Memory quiz-for example, Did it rain yesterday? What did you have for breakfast? (b) Kim's game (written words and numbers as well as objects on the tray; gradually increased in difficulty). (c) Bridge.

Numbers.-(a) Speed and ability at number games such as dice, cards, and bingo. (b) Scoring at darts, etc. (by both written and mental arithmetic). (c) For those who like it, books of sums, done over many months with each page dated.

Money.-(a) Recognition of new currency. (b) Speed and ability at decimal currency games. (c) Shopping and accurate change-giving (practised at home and in the shops).

Time.-(a) Dummy clock-face quiz - for example, put the hands to tea time; move them 1 hour 20 minutes, etc. (b) Whether or not the patient is ready when volunteers call and for other events (done in co-operation with the family).

Calendar.- (a) Calendar quiz - for example, point to your birthday, to last Sunday, first day of June, period of winter, etc. (b) In some cases a diary is kept with signs and words and checked for accuracy.

Shapes.-(a) Jigsaw-for example, from six pieces in half an hour to 100 in two hours. (b) Games involving shapes such as a form of snap or shape bingo.

Colours.-(a) Colour quiz (possibly using crayons and paints)-for example, match yellow to yellow, pick out green, pick grass colour, shade from brown to red. (b) In some cases painting.

Observation.-(a) Car runs or walks; questions asked during run and on return; identification of the route. (b) What the patients notice is checked at the club usually with reference to each other.

Alertness.-There is no problem in recognizing improvement here.

Concentration.- (a) How quickly do volunteers have to change subjects? (b) How long can a game be played ? Progression from simple card games to bridge.

\section{References}

${ }^{1}$ British Medical fournal, 1974, 4, 122.

2 Griffith, V. E., A Stroke in the Family. London, Wildwood House, 1975.

University Department of General Practice, Aberdeen AB9 2ZD

R. J. TAYLOR, M.B., M.R.C.G.P., Lecturer

J. G. R. HOWIE, M.D., M.R.C.G.P., Senior Lecturer

The Laboratory, City Hospital, Aberdeen AB9 8AU

J. BRODIE, M.D., F.R.C.PATH., Consultant in Charge

I. A. PORTER, M.D., F.R.C.PATH., Consultant Bacteriologist

Aberdeen differed widely. The doctors who made most
use of the laboratory service rarely did so equally for all
four investigations but usually for orly one or two.
Similarly, those who used the service least often made
frequent use of one particular investigation. Further
studies are needed to identify and evaluate the reasons
for the apparently substantial disagreement among
general practitioners concerning the value of these diff-
ferent bacteriological investigations in general practice.

\section{Introduction}

General practitioners vary considerably in their use of laboratory services. ${ }^{1-5}$ Most large studies have divided them into "high" and "low" users on the basis of use of complete specialty 